\title{
$1 \quad$ Microbial ecology of watery kimchi
}

3 Kyu Hang Kyung ${ }^{\mathrm{a}}$, Eduardo Medina Pradas ${ }^{\mathrm{b}, \mathrm{f}}$, Song Gun Kim ${ }^{\mathrm{c}}$, Yong Jae Lee ${ }^{\mathrm{c}}$, Kyong Ho Kim ${ }^{\mathrm{d}}$,

4 Jin Joo Choi ${ }^{\mathrm{e}}$, Joo Hyong Cho ${ }^{\mathrm{e}}$, Chang Ho Chung ${ }^{\mathrm{e}}$, Rodolphe Barrangou ${ }^{\mathrm{f}}$, Frederick Breidt ${ }^{\mathrm{g}}$.

$6 \quad{ }^{\mathrm{a}}$ Department of Food Science, Sejong University, 98 Gunja-dong, Gwangjin-gu, Seoul, 143-747,

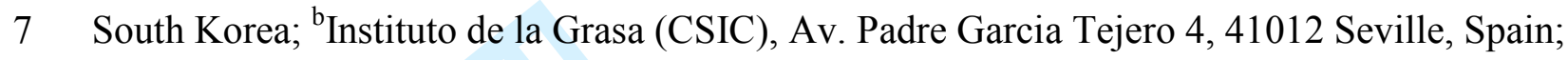

$8{ }^{\mathrm{c}}$ Microbial Resource Center/KCTC, Korea Research Institute of Bioscience and Biotechnology,

9 Daejeon 305-806, Republic of Korea; ${ }^{\mathrm{d}}$ Department of Microbiology, Pukyong National

10 University, Pusan 608-737, South Korea; ${ }^{\mathrm{e} D e p a r t m e n t ~ o f ~ C u l i n a r y ~ S c i e n c e ~ a n d ~ F o o d ~ S e r v i c e ~}$

11 Management, Sejong University, 98 Gunja-dong, Gwangjin-gu, Seoul, 143-747, South Korea;

$12{ }^{\mathrm{f}}$ Department of Food, Bioprocessing and Nutrition Sciences, 400 Dan Allen Drive, North

13 Carolina State University, Raleigh, NC 27695-7624; ${ }^{\mathrm{g} U S D A}-A R S$, SAA Food Science Research

14 Unit, 322 Schaub Hall, Box7624, North Carolina State University, Raleigh, NC 27695-7624

$16{ }^{*}$ Corresponding author: Dr. Frederick Breidt, Jr. (E-mail: Fred.Breidt@ars.usda.gov)

18 Running title: Watery Kimchi (Nabak and Dongchimi) Ecology

19 Word count: 4,189

21 Mention of a trademark or proprietary product does not constitute a guarantee or warranty of the

22 product by the U. S. Dept. of Agriculture or North Carolina Agricultural Research Service, nor

23 does it imply approval to the exclusion of other products that may be suitable. 
24 Abstract: The biochemistry and microbial ecology of two similar types of watery ( $m u l$ kimchi,

25 including sliced and unsliced radish and vegetables (nabak and dongchimi, respectively), were

26 investigated using traditional microbiological methods, high performance liquid chromatography

27 and high throughput DNA sequencing at three temperatures $\left(4^{\circ} \mathrm{C}, 10^{\circ} \mathrm{C}\right.$, and $\left.20^{\circ} \mathrm{C}\right)$. The objective

28 of the research was to survey of the microbial ecology of $m u l$ kimchi under a variety of

29 processing conditions, including sliced and unsliced (nabak and dongchimi) at a three

30 temperatures $\left(10^{\circ}, 20^{\circ}\right.$, and $\left.30^{\circ} \mathrm{C}\right)$ to determine changes in radish preparation and different

31 fermentation temperatures affected both the biochemistry and microbiota of $m u l$ kimchi. Sliced

32 nabak kimchi showed similar trends for the changes in biochemistry (lactic and acetic acids, $\mathrm{pH}$ )

33 as dongchimi kimchi for each temperature, but differences in microbiota were apparent.

34 Interestingly, bacteria from the Proteobacterium phylum, including Enterobacteriaceae,

35 decreased more rapidly in sliced nabak cabbage fermentations compared to dongchimi at $4^{\circ} \mathrm{C}$.

36 Although changes for these populations were similar at $10^{\circ} \mathrm{C}$ and $20^{\circ} \mathrm{C}$, the homolactic stage of

37 fermentation was not developed for the $4^{\circ} \mathrm{C}$ and $10^{\circ} \mathrm{C}$ samples of both nabak and dongchimi by

38 the end of the sampling time. These data show the differences in biochemistry and microbial

39 ecology that can result from preparation method and fermentation conditions of the kimchi

40 which may impact safety and quality of the product. In addition, the data also illustrate the need

41 for improved methods for microbial ecology for closely related LAB species.

43 Keywords: Watery kimchi, High throughput sequencing, microbial ecology 


\section{Introduction}

There are many different kinds (perhaps hundreds) of fermented vegetable kimchi, a

47 traditional food of Korea, which can be roughly classified into two groups based on processing

48 method, with or without added brine for fermentation (Cheigh and Park 1994). These

49 fermentations are typically prepared with flavoring ingredients included and do not require

50 further processing or desalting prior to consumption. Typically, salt concentrations of 2-3\%

51 sodium chloride (equilibrated) are used for fermentation. A common ingredient in many types of

52 kimchi is Chinese cabbage (Brassica compestries) used in traditional chopped baechu or whole

53 cabbage (tongbaechu) kimchi. Other common types of include radish (Raphanus spp.) kimchi

54 varieties, including kakdugi (cubed) and yeolmoo (whole small radishes) kimchi, and others.

55 Watery kimchi ( $m u l$ kimchi) is fermented with water (or salt brine) added to the vegetables, to

56 typically exceed two or more times the volume of the vegetables. Varieties $m u l$ kimchi include

57 biak kimchi (with baechu cabbage as the main vegetable ingredient), dongchimi (with whole or

58 quartered radish), and nabak kimchi (with thinly sliced radish). A variety of other vegetable

59 ingredients may also be included in mul kimchi as minor constituents.

60 The changes in microbial populations during baechu kimchi and dongchimi fermentation

61 have been documented by isolate-based and high throughput DNA sequencing methods (Cheigh

62 and Park 1994; Fleming and others 1995; Park and others 2009; Jeong and others 2013; Jung and

63 others 2014). It is evident that the rate of reduction in $\mathrm{pH}$, biochemistry and microbial

64 populations are dependent on temperature (Mheen and Kwon 1984; Lee and others 2005; Cho

65 and others 2006; Park and others 2008). A study of beachu kimchi fermentation isolates using

66 16S rDNA sequencing has shown that Leuconostoc spp. and Weissella spp. predominated at

$6710^{\circ} \mathrm{C}$ and $15^{\circ} \mathrm{C}$ during the initial stage of fermentation, with Leuconostoc gasicomiatum and 
68 Leuconostoc citrium predominating during the first $4 \mathrm{~d}$ of fermentation at $15^{\circ} \mathrm{C}$ (Jeong and others

69 2013). At $10^{\circ} \mathrm{C}$ or colder Weissella koreensis has been found to be the dominant species, with

70 fermentation occurring by this organism at temperatures as low as $-1{ }^{\circ} \mathrm{C}$.

71 A microbial ecology study of dongchimi at $5^{\circ} \mathrm{C}$ and $25^{\circ} \mathrm{C}$ using culture based and

72 denaturing gradient gel electrophoresis methods showed discrepancies between the two methods,

73 but isolates showed similar species at $5^{\circ} \mathrm{C}$ and $25^{\circ} \mathrm{C}$, with Leuconostoc mesenteroides as the

74 dominant organism during the first 3 to $7 \mathrm{~d}$ of fermentation (Park and others 2008). A more rapid

75 decline in $\mathrm{pH}$ and increase in lactic acid bacterial populations were seen at $25^{\circ} \mathrm{C}$ compared to

$765^{\circ} \mathrm{C}$. A study of dongchimi with of the evolution of microbial populations during a fermentation

77 at $4^{\circ} \mathrm{C}$ for $90 \mathrm{~d}$ using 454 sequencing technology showed that Leuconostoc species predominated

78 during fermentation (Jeong and others 2013). A variety of Leuconostoc species and Weissella

79 were evident during the first $3 \mathrm{~d}$ of fermentation, however, two species, Le. gasicomitatum and

80 Le. gelidum were the predominant species for the remainder of the $90 \mathrm{~d}$ sampling period. In

81 another study, the ecology of nabak kimchi showed changes in the number of lactic acid bacteria

82 (LAB) isolates using selective media for Leuconostoc spp. and Lacobacilli spp (Kong and others

83 2005). Both groups had high numbers $\left(10^{6-7} \mathrm{CFU} / \mathrm{mL}\right)$ after the initiation of fermentation.

84 Leuconostoc spp. were able to grow slowly at $5^{\circ} \mathrm{C}$ while Lactobacilli did not. The growth rates of

85 these species were proportional to temperature, increasing at $10^{\circ} \mathrm{C}$ and $20^{\circ} \mathrm{C}$, but growth rate

86 decreased when acid levels increased.

87 We conducted a survey of the microbial ecology of $m u l$ kimchi under a variety of

88 processing conditions, including sliced and unsliced (nabak and dongchimi) at three temperatures

$89\left(10^{\circ} \mathrm{C}, 20^{\circ} \mathrm{C}\right.$ and $\left.30^{\circ} \mathrm{C}\right)$ to determine how changes in radish preparation and fermentation

90 temperature affected both the biochemistry and the microbiota. While quality factors were not 
91 directly investigated in this study, our work represents an important initial step for determining

92 how processing conditions (slicing, fermentation temperature) may influence the chemistry and

93 microbiota.

94

95 MATERIALS AND METHODS

96 Preparation of watery kimchi and sampling

97 Laboratory-scale batches of mul kimchi were prepared with $3.6 \mathrm{~L}$ glass containers with

98 lids. Ingredients for watery kimchi used in this study were purchased from a local market in

99 Seoul, S. Korea in 2013. Each batch of watery kimchi was prepared with $1.5 \mathrm{~kg}$ of distilled

100 water, $1 \mathrm{~kg}$ of radish, $50.36 \mathrm{~g}$ of salt, $10 \mathrm{~g}$ of green onion, $5 \mathrm{~g}$ of garlic, and $3 \mathrm{~g}$ of ginger. Radish

101 (in length 17-23 cm and with a diameter of $8-10 \mathrm{~cm}$ ) was washed with water, trimmed, and cut

102 into quarters along the long axis for dongchimi, or further sliced into about $0.5-1 \mathrm{~cm}$ thick thin

103 pieces for nabak kimchi. For both dongchimi and nabak kimchi preparations, green onion, garlic,

104 and ginger were added. Prepared materials were placed in jars which were placed at 4, 10, and

$10520^{\circ} \mathrm{C}$ as indicated in Table 1 . Brine samples $(10 \mathrm{ml})$ were collected and processed for traditional

106 microbiological methods, then stored at $-70^{\circ} \mathrm{C}$ prior to biochemical analysis and microbial DNA

107 sampling.

108

109 Microbial and biochemical analyses

110 Total aerobic plate count, total LAB, and dextran-producing LAB were estimated by

111 plating dilutions of the brine on Plate Count Agar (Difco Laboratories Inc., Detroit, Mich,

112 U.S.A.), deMan, Rogosa and Sharpe (MRS) agar with $0.05 \%$ sodium azide, and peptone-yeast

113 (PY) sucrose agar (10 g peptone, $5 \mathrm{~g}$ yeast extract, $20 \mathrm{~g}$ sucrose, and $15 \mathrm{~g}$ agar/L) with $0.05 \%$ 
114 sodium azide, (respectively), followed by incubation for 1 to $4 \mathrm{~d}$ at $30^{\circ} \mathrm{C}$. Measurements of

115 titratable acidity (TA) were done using aliquots of $0.1 \mathrm{~N}$ sodium hydroxide to an end point of $\mathrm{pH}$

1168.2 ; TA was calculated as percent lactic acid equivalent. After dilution and filtration $(0.2 \mu \mathrm{m}$

117 membrane), brine samples were injected in a High-Performance Liquid Chromatography

118 (HPLC) system for the analysis of sugars, and organic acids. Sugar and ethanol analyses were

119 done by HPLC using Aminex HPX-87C column (300 mm X 7.8 mm, Bio-rad., Hercules, Calif.,

120 U.S.A.) and a refractive index detector (RI-410, Bio-rad). The samples were eluted at $0.6 \mathrm{ml}$

$121 \mathrm{~min}^{-1}$ with a $0.01 \mathrm{M}$ potassium sulfate solution. Organic acids concentrations were also measured

122 by HPLC. For organic acids, samples were run on an Luna C18 column (250 mm X $4.2 \mathrm{~mm}$,

123 Phenomenex, Torrance, CA) and analyzed with a UV detector (Waters 2487, at $210 \mathrm{~nm}$ ) run at

$12440^{\circ} \mathrm{C}$ with $0.05 \mathrm{M}$ monopotassium phosphate adjusted to $\mathrm{pH} 2.8$ as the eluent, and a flow rate of

$1250.5 \mathrm{ml} \mathrm{min}^{-1}$. Protonated organic acids were calculated based from the $\mathrm{pH}$ and acid concentration 126 data using the Henderson-Hasselbalch equation, based on $\mathrm{pK}_{\mathrm{a}}$ values of 3.86 and 4.76 for lactic 127 and acetic acids, respectively.

129 Bacterial 16S rDNA gene amplification and pyrosequencing

130 Ten $\mathrm{ml}$ of $m u l$-kimchi brine, including solid particles was filtered by a $0.2 \mu \mathrm{m}$ filter

131 paper. The filter paper was ground with glass beads under liquid nitrogen. Then, DNA was

132 extracted by the instructions of MoBio Power Soil DNA Isolation kit (MoBio Laboratories, Inc.,

133 Carlsbad, Calif., U.S.A.). Hypervariable regions (V3 through V6) of the 16s rDNA were

134 amplified by PCR from total bacterial DNA using forward and reverse primers described by

135 Klindworth and others 2013. PCR Primers included leader sequences and barcodes, and were

136 designed according to the WM Keck Center sequencing facility instructions for 454 sequencing 
137 (http://www.biotech.uiuc.edu/centers). The forward primer included a leader sequence, barcode

138 and bacterial $16 \mathrm{~S}$ specific primer starting at approximately base 341 of the rDNA gene:

139 S-D-Bact-0341-b-S-17 (5'- CCTACGGGNGGCWGCAG - 3') and the reverse primer contained

140 a leader and 16S primer sequence (approximate base 1061): S-D-Bact-1061-a-A-17 (5'-

141 CRRCACGAGCTGACGAC - 3') (Klindworth and others 2013). Sequencing was done

142 unidirectionally, so there was no reverse primer barcode. The PCR reactions contained 5-10 ng

143 of DNA template, $0.25 \mathrm{uL}$ of FastStart HIFI Polymerase (5 U/ug) (Roche, Mannhein, Germany),

$1442.5 \mathrm{uL}$ FastStart 10X buffer, $0.5 \mathrm{uL}$ of dNTP mix (10 mM each) and $0.4 \mathrm{uM}$ of each primer.

145 Reaction conditions consisted of an initial denaturation for $2 \mathrm{~min}$ at $95^{\circ} \mathrm{C}$ followed by 30 cycles

146 of $94^{\circ} \mathrm{C}$ for $30 \mathrm{~s}, 60^{\circ} \mathrm{C}$ for $30 \mathrm{~s}$ and $72^{\circ} \mathrm{C}$ for $60 \mathrm{~s}$, and a final extension of $72^{\circ} \mathrm{C}$ for $7 \mathrm{~min}$. The

147 PCR products with approximately 800 nucleotides were confirmed by gel electrophoresis in a

$148 \quad 1 \%$ agarose gel and purified using MinElute Gel Extraction Kit (Qiagen, Valencia, Calif.,

149 U.S.A.). DNA concentrations of amplicons were quantified using AccuClear dsDNA

150 Quantification kit (Biotium, Hayward, Calif., U.S.A.) on a 96-well plate reader. The barcoded

151 PCR products were then mixed at equimolar concentrations into 3 samples, and submitted to the

152 Carver Biotech Laboratory at the WM Keck Center for Comparative and Functional Genomics

153 (Chicago, Ill., U.S.A.) for 454 platform sequencing.

155 Sequencing analysis

156 Data files obtained from the Carver Laboratory included .fna (FASTA format) and .qual

157 (quality score) DNA sequencing analysis files. A mapping file was prepared relating the

158 sequence barcode data to sample identifiers. Files were processed with the QIIME pipeline of

159 Python program scripts (http://qiime.org/index.html). Sequences were initially edited based on 
160 quality scores and length using default QIIME parameters, including (minimum 454 sequencing

161 quality score $=25$ ). The sequences were then binned by barcode, and the barcodes and primer

162 sequences removed. Operational taxonomic units (OTUs) were identified by sequence similarity

163 among the reads. The identity for each OTU was determined using a Greengenes database

164 (http://greengenes.lbl.gov, version 13_5) with the RDP or BLAST classifier

165 (http://rdp.cme.msu.edu/) using QIIME python scripts at the default 97\% and 99\% identity levels

166 (Kuczynski and others 2011), as described below. For beta diversity, UniFrac distances were

167 determined between all pairs of samples (Lozupone and others 2006). UniFrac-based jackknifed

168 hierarchical cluster was constructed using unweighted pair group method with arithmetic mean

169 (UPGMA) in QIIME. Principal component analysis was also performed on the UniFrac distance

170 matrices and visualized by QIIME. Additional data analysis was done with custom python scripts

171 to extract selected OTU populations for BLAST analysis as indicated in the text. Accession

172 numbers: NCBI Genbank database (accession numbers applied for).

173

174 RESULTS

175 A summary of the sampling times and temperatures, as well as the numbers of DNA

176 sequences for the two types of mul-kimchi, dongchimi (unsliced) and nabak (sliced) is presented

177 in Table 1. For both types of kimchi, the decrease in $\mathrm{pH}$ varied with temperature, but only

178 showed a $0.2 \mathrm{pH}$ unit or less difference due to type (dongchimi vs. nabak), as shown in Figure 1.

179 At $20^{\circ} \mathrm{C}$, nabak kimchi had $26 \mathrm{mM}(+/-0.03 \mathrm{mM})$ lactic acid at $7 \mathrm{~d} v \mathrm{~s} .17 \mathrm{mM}(+/-0.2 \mathrm{mM})$

180 lactic acid for dongchimi kimchi (Figure 2), although the $\mathrm{pH}$ was approximately 3.3 for both

181 preparations. This trend was also apparent for acetic acid, but was less pronounced, with only a

182 2-5 $\mathrm{mM}$ difference between the two types of kimchi. The release of nutrients by slicing the 
183 radish was apparent for nabak compared to dongchimi kimchi. The diffusion rate for nutrients

184 and sugars may be higher in the nabak fermentation compared to the dongchimi, as indicated by 185 both the acid production data (Figure $2 \mathrm{~A}$ and $2 \mathrm{~B}$ ) and the sugar data (Figures $3 \mathrm{~A}$ and $3 \mathrm{~B}$ ) where 186 nabak had high free sugar concentrations than dongchimi for most of the time.

187 The total aerobic plate count and LAB plate count data were similar (Figure 4), and the

188 PY cell count data did not differ substantially from the MRS data (data not shown). For all 189 sampling times, only nabak had LAB cell counts that exceeded $10^{8} \mathrm{CFU} / \mathrm{ml}$, which was recorded

190 for the $3 \mathrm{~d}$ samples at $20^{\circ} \mathrm{C}$, and the $14 \mathrm{~d}$ sample at $10^{\circ} \mathrm{C}$. In both cases the maximum CFU/ml 191 values were achieved when the calculated protonated acid concentrations (data not shown) were 192 around $3.0(\mathrm{C} 2003)$ and $3.5 \mathrm{mM}(\mathrm{C} 1014)$ for lactic acid, and the protonated acetic acid 193 concentrations were 3.3 (C2003) and $8.3 \mathrm{mM}(\mathrm{C} 1014)$.

194 Sequencing of nabak and dongchimi kimchi resulted in 3000 and 9000 qualified reads for 195 each sample, with an average of 5657 reads/sample. There were a total of 19,988 sequences in 196 the representative set of OTUs defined by the QIIME software (for 97\% identity) for the 197 dongchimi samples, and 15,341 representative OTUs for the nabak samples. The average 198 sequence length was $722.2+/-68.3$ bp for dongchimi, and $720.6+/-72.5$ bp for the nabak 199 kimchi.

$200 \quad$ Bacterial population profiles between nabak and dongchimi kimchi preparations are 201 shown in Figure 5. Comparisons at each temperature showed that sequences representative of the 202 family Enterobacteriaceae were reduced in nabak vs. dongchimi kimchi. Similarly, sequences 203 from the genus Leuconostoc were in greater total abundance in nabak fermentations compared to 204 the same temperature for the dongchimi fermentation sample, although other members of the 205 family Leuconostocaceae not identified to the genus level as Leuconostoc had a greater 
206 abundance in dongchimi kimchi. In the $20^{\circ} \mathrm{C}$ samples of both nabak and dongchimi kimchi, OTU 207 sequences representative of the order Lactobacillales (identified only to the order level)

208 dominated the fermentations by the $5^{\text {th }}$ day of fermentation $(>60 \%$, Figures 5 and 6$)$. To further

209 identify these sequences, they were extracted using a python script (F. Breidt, unpublished) and

210 subjected to BLASTN analysis using the Greengenes Megablast algorithm and the Greengenes

$21199 \%$ level identity rDNA sequence database (version 13_5). For dongchimi 7 d samples (N2007)

21242 of 151 Lactobacillales OTUs remained identified to the order level only (primarily to 3

213 specific sequences in the database), and 20 OTUs were identified only as the family

214 Lactobacillaceae. The majority of the remainder was identified to the genus level as:

215 Lactobacillus (51 OTUs), Leuconosotoc (22 OTUs), or Lactococcus (7 OTUs). For the nabak

216 samples, 104 of 195 sequences were identified only to the order Lactobacillales. These

217 sequences were not further classified by the BLAST analysis, and were primarily represented by

218 the same 3 database sequences found for nabak samples. The remainder mostly consisted of

219 sequences identified only as representative of the family Lactobacillaceae (28 OTUs), as well as

220 genera Lactobacillus (14 OTUs), Leuconostoc (29 OTUs), and Lactococcus (10 OTUs). For a

221 broad picture of the changes in microbial ecology during fermentation, representatives of the

222 phyla Proteobacteria (including Enterobacteriaceae) and Fermicutes (including LAB) are

223 shown in Figure 7. Interestingly, a difference between nabak and dongchimi was seen for $4^{\circ} \mathrm{C}$,

224 but patterns for the changing populations were similar at $10^{\circ} \mathrm{C}$ and $20^{\circ} \mathrm{C}$. Further research will be 225 necessary to confirm these patterns.

226 The estimators for bacterial alpha diversity, including Chao1, Simpson, and Shannon

227 values are shown in Table 2 . The greatest diversity was seen with the fresh radish samples

228 (C0000 and N0000). In general, diversity decreased with fermentation time, although there was 
229 no clear trend for all samples, particularly for the $10^{\circ} \mathrm{C}$ samples for both nabak and dongchimi.

230 Clustering by UPGMA tree analysis indicated a clear difference for the unfermented fresh

231 ingredients (Figure 7A) compared to the fermented products for both nabak and dongchimi,

232 however there was no clear clustering of samples either by UPGMA tree or principal component

233 analysis (Figure 7B) for either nabak vs. dongchimi or temperature of fermentation.

235 DISCUSSION

236 Traditionally fermented 'natural' vegetable products are growing popularity. For many fermented 237 vegetable products the microbial ecology has recently been updated from traditional microbial studies by 238 a variety of molecular techniques, including various types of kimchi and cabbage fermentations (Cheigh 239 and Park 1994; Lee and others 2005; Cho and others 2006; Plengvidhya and others 2007; Kim and others 240 2012; Jung and others 2014). Often overlooked in these studies, however, is the effect of processing 241 conditions and ingredients on microbial ecology, which may influence both the quality and safety of these 242 products. Our study of nabak and dongchimi kimchi, which differ by slicing method for the main (radish)

243 ingredient showed some interesting differences microbiota for samples at $4{ }^{\circ} \mathrm{C}$, although they had a similar

244 biochemistry. It is interesting that similar biochemical values for lactic and acetic acids, and $\mathrm{pH}$ at $4^{\circ} \mathrm{C}$

245 (Figures 1 and 2) gave different results for the microbiota (Figures 5A, 6A and 7A). At $10^{\circ} \mathrm{C}$ and $20^{\circ} \mathrm{C}$

246 differences in microbiota were less apparent that at $4^{\circ} \mathrm{C}$. These data indicate that at colder temperatures

247 (4 $\mathrm{C})$ the competition between LAB (Firmicutes) and other epiphytic bacteria in the phylum

248 Proteobacteria, such as Enterobaceriaceae, Pesudomonads, and others may be affected by relatively

249 small changes in environment brought about by slicing $v s$. not slicing the radish vegetable material,

250 possibly due to the slower growth rates of the competing organisms. It is also apparent that for the $4^{\circ} \mathrm{C}$

251 and $10^{\circ} \mathrm{C}$ samples of both nabak and dongchimi kimchi that the homolactic stage of fermentation was not

252 developed by the end of the experiment. The delayed onset of homolactic fermentation can result in a 
253 higher quality, lightly fermented product. Further study will be needed to determine how quality of nabak 254 and dongchimi is related to the cutting method.

At $20^{\circ} \mathrm{C}$, the nabak kimchi had $26 \mathrm{mM}$ lactic acid vs. $17 \mathrm{mM}$ lactic acid for dongchimi after a 256 similar time of fermentation (7 d), but surprisingly these samples both had a $\mathrm{pH}$ of 3.3. It is possible that 257 buffering in the brine was affected by the different preparation methods and rates at which acids and other 258 buffering compounds diffused into the brine. Similarly, the relation between sugar concentration and 259 fermentation time indicated a more rapid diffusion for nabak samples (Figure 3). Sugar concentration 260 changes did not show a consistent pattern, however, because diffusion of free sugars from the radish and 261 consumption of sugar by LAB were concurrent. Metabolism of the sugar continued to occur after the time 262 when the maximum cell concentration was recorded, as indicated by the continued change in sugar 263 concentration (Figure 3). The protonated lactic and acetic acid concentrations were presumably 264 responsible for preventing further cell division and the subsequent decline in cell numbers of LAB, 265 because sugar was still present at these time-points.

For further analysis of dongchimi and nabak kimchi, a high throughput 16S rDNA sequencing was

267 used. Because LAB are known to have similar 16S sequences (Singh and others 2009), a 454

268 pyrosequencing sequencing strategy was used that could generate 700 to 800 base pair (bp) or greater 269 sequencing reads. Other next generation sequencing technologies generate shorter reads (Quail and others 270 2012) which would decrease the ability to discriminate closely related LAB species. PCR primers were 271 selected for optimum phylogenetic coverage of the domain bacteria, and were chosen to amplify a 272 fragment covering variable regions 3, 4, and 5 (based on the Escherichia coli 16S rDNA positions) 273 (Klindworth and others 2013). This region has been shown by in-silico analysis to give $85 \%$ or greater 274 classification accuracy for bacterial species at the genus level (Wang and others 2007). For the $20^{\circ} \mathrm{C}$ 275 samples for nabak and dongchimi, however, we were unable to obtain identification of OTUs beyond the 276 order level (order Lactobacillales) for the majority of sequences. The limited ability to identify 
277 sequences beyond the order or family level was apparently due to OTUs matching

278 uncharacterized sequences in the database.

279 One drawback of using DNA based methods for microbial ecology in vegetable fermentations is

280 that data on the relative abundance of OTUs may be biased by DNA that was amplified from dead or

281 non-viable cells (Plengvidhya and others 2007). This scenario is unlikely, however, because of the decline

282 in species observed during the time-course of the nabak and dongchimi fermentations (Figures 5 and 6). It

283 is likely that nuclease present in fermentations was responsible for the degradation of extracellular DNA

284 from species that decline in numbers during the fermentation.

285 In agreement with a previous report (Jeong and others 2013), we found relatively few sequences

286 representative of the genus Weissella, however, the $700 \mathrm{bp} 16 \mathrm{~S}$ sequences were only sufficient to identify

287 some OTUs to the family or order (Leuconostocaceae or Lactobacillales, respectively) level at 97\%

288 identity, which was used for our analysis. Previous studies with isolated cultures from kimchi and related

289 vegetable fermentations have identified heterolactic isolates as L. mesenteroides, L. citrium, and Weissella

290 species (family Leuconostocaceae ) and homolactic isolates as Lactobacillus plantarum (order

291 Lactobacillales) (Mheen and Kwon 1984; Plengvidhya and others 2007; Kim and others 2012). A variety

292 of methods for differentiating closely related species of LAB have been developed (Singh and others

293 2009), but a metagenomics approach may be the best way to more precisely define microbial

294 communities with of species with similar 16S sequences. Further research may also be needed to

295 characterize the consistency of microbial changes in nabak and dongchimi kimchi fermentations and

296 vegetable fermentations in general. These data may support subsequent studies relating microbiota

297 to product quality.

299 ACKNOWLEDGEMENTS

300 This work was carried out as part of the international collaborative R\&D program funded 13 
301 by the Agency for Korea National Food Cluster (2013), and supported in part by a grant from

302 Pickle Packers Intl. Inc., Washington, D.C. We thank the Spanish Government (MECD) for the 303 postdoctoral fellowship support for Dr. E. Medina-Pradas. 


\section{REFERENCES}

305 Cheigh HS, Park KY. 1994. Biochemical, microbiological, and nutritional aspects of kimchi 306 (Korean fermented vegetable products). Crit Rev Food Sci Nutr 34(2):175-203.

307 Cho J, Lee D, Yang C, Jeon J, Kim J, Han H. 2006. Microbial population dynamics of kimchi, a 308 fermented cabbage product. FEMS Microbiol Lett 257:262-267.

309 Fleming HP, Kyung KH, Breidt F. 1995. Vegetable fermentations. In: Rehm HJ, Reed G, 310 editors.Biotechnology, vol. 9. Enzymes, Biomass, Food and Feed, 2nd ed. New York: VCH 311 Publishers, Inc. p 629-661.

312 Jeong SH, Jung JY, Lee SH, Jin HM, Jeon CO. 2013. Microbial succession and metabolite 313 changes during fermentation of dongchimi, traditional Korean watery kimchi. Int J Food $314 \quad$ Microbiol 164:46-53.

315 Jung JY, Lee SH, Jeon CO. 2014. Kimchi microflora: history, current status, and perspectives for 316 industrial kimchi production. Appl Microbiol Biotechnol (doi:10.1007/s00253-014-5513-1) $317 \quad 1-9$

318 Kim B, Seo WT, Kim MG, Yun HD, Cho KM. 2012. Metagenomic lactic acid bacterial diversity 319 during Mulkimchi fermentation based on 16S rRNA sequence. J Korean Soc Appl Biol $320 \quad$ Chem 55(6):787-792.

321 Klindworth A, Pruesse E, Schweer T, Peplies J, Quast C, Horn M, Glockner FO. 2013.

322 Evaluation of general 16S ribosomal RNA gene PCR primers for classical and 
next-generation sequencing-based diversity studies. Nucelic Acids Res 41(1), e1 (doi:10.1093/nar/gks808) 1-11.

325

326

327

328

329

330

331

332

333

334

335

336

337

338

339

340

341

342

Kuczynski J, Stombaugh J, Walters WA, Gonzalez A, Caporaso JG, Knight R. 2011. Using QIIME to analyze 16S rRNA gene sequences from microbial communities. Current Protocols in Bioinformatics. John Wiley \& Sons. NY, NY. Ch 10:10.7 (doi: 10.1002/0471250953.bi1007s36).

Lee JS, Heo GY, Lee JW, Oh YJ, Park JA, Park YH, Pyun YR, Ahn JS. 2005. Analysis of kimchi microflora using denaturing gradient gel electrophoresis. Int J Food Microbiol 102(2):143-150.

Lozupone C, Hamady M., Knight R. 2006. UniFrac -- An online tool for comparing microbial community diversity in a phylogenetic context. BMC Bioinf 7:371.

Mheen TI, Kwon TW. 1984. Effect of temperature and salt concentration on kimchi fermentation. Korean J Food Sci Technol 16(4):443-450.

Park EJ, Chang HW, Kim KH, Nam YD, Roh SW, Bae JW. 2009. Application of quantitative real-time PCR for enumeration of total bacterial, archaeal, and yeast populations in kimchi. J Microbiol (Korea) 47(6):682-685.

Park SJ, Chang JH, Cha SK, Moon GS. 2008. Microbial analysis of dongchimi, Korean watery radish kimchi, at the early and mid-phase fermentation. Food Sci Biotechnol 17(4): 892-894.

Plengvidhya V, Breidt F, Lu Z, Fleming HP. 2007. DNA fingerprinting of lactic acid bacteria in 

sauerkraut fermentations by methods. Appl Environ Microbiol 73(23):7697-7702.

344 Quail MA, Smith M, Coupland P, Otto TD, Harris SR, Connor TR, Bertoni A, Swerdlow HP, Gu 345 Y. 2012. A tale of three next generation sequencing platforms: comparison of Ion Torrent, 346 Pacific Biosciences and Illumina MiSeq sequencers. BMC Genomics 13:341-354.

347 Singh S, Goswami P, Shigh R, Heller KJ. 2009. Application of molecular identification tools for 348 Lactobacillus, with a focus on discrimination between closely related species: A Review.

$349 \quad$ LWT-Food Sci Technol 42:448-457.

350 Kong CS, Seo JO, Bak SS, Rhee SH, Park KY. 2005. Standardization of manufacturing methods, 351 lactic acid bacterial growth, and $\mathrm{CO}_{2}$ levels of nabak kimchi at different temperatures. The 352 Korean Soc Food Sci Nutr 34(5):707-714 (in Korean).

353 Wang Q, Garrity GM, Tiedje JM, and Cole JR. 2007. Naive Baysian classified for rapid 354 assignment of rRNA sequences into the new bacterial taxonomy. Appl Environ Microbiol $355 \quad 73(16): 5261-5267$. 
356 Table 1. Experimental design and sequence data

\begin{tabular}{|c|c|c|c|c|}
\hline Sample & Type & Temp $\left({ }^{\circ} \mathrm{C}\right)$ & Time(D) & No. Reads \\
\hline C0000 & Sliced, Nabak & NA $^{\mathrm{a}}$ & 0 & 6515 \\
\hline C0407 & Sliced & 4 & 7 & 6628 \\
\hline C0414 & Sliced & 4 & 14 & nd $^{\mathrm{c}}$ \\
\hline C0421 & Sliced & 4 & 21 & 4696 \\
\hline C0430 & Sliced & 4 & 30 & 4189 \\
\hline C1003 & Sliced & 10 & 3 & nd \\
\hline C1007 & Sliced & 10 & 7 & 6895 \\
\hline C1014 & Sliced & 10 & 14 & 7332 \\
\hline C1021 & Sliced & 10 & 21 & 8235 \\
\hline C2001 & Sliced & 20 & 1 & 5782 \\
\hline C2003 & Sliced & 20 & 3 & 4306 \\
\hline C2005 & Sliced & 20 & 5 & 6005 \\
\hline C2007 & Sliced & 20 & 7 & nd \\
\hline \hline N0000 & Unsliced, Dongchimi & NA & 0 & 2396 \\
\hline N0407 & Unsliced & 4 & 7 & 8502 \\
\hline N0414 & Unsliced & 4 & 14 & 8748 \\
\hline N0421 & Unsliced & 4 & 21 & 3305 \\
\hline N0430 & Unsliced & 4 & 30 & 5183 \\
\hline N1003 & Unsliced & 10 & 3 & 4792 \\
\hline N1007 & Unsliced & 10 & 7 & 8827 \\
\hline N1014 & Unsliced & 10 & 14 & 3828 \\
\hline N1021 & Unsliced & 10 & 21 & 4354 \\
\hline N2001 & Unsliced & 20 & 1 & 6112 \\
\hline N1003 & Unsliced & 20 & 3 & 3320 \\
\hline N2005 & Unsliced & 20 & 5 & 4283 \\
\hline N2007 & Unsliced & 20 & 7 & 5868 \\
\hline & & & & \\
\hline
\end{tabular}

a NA, not applicable, fresh cabbage sample

${ }^{b}$ No. Reads, number of DNA sequences used for analysis

${ }^{\mathrm{c}}$ nd, not determined 
359 Table 2. Species diversity estimators calculated from 1000 sequences randomly chosen from the

360 reads of kimchi samples.

361

\begin{tabular}{|c|c|c|c|c|c|}
\hline Sample $^{\mathrm{a}}$ & OTUs $^{\mathrm{b}}$ & Chao $^{\mathrm{c}}$ & Simpson $^{\mathrm{c}}$ & Shannon $^{\mathrm{c}}$ & \\
\hline C0000 & 167.3 & 378.2 & 0.874 & 4.71 & \\
\hline C0407 & 97.6 & 236.0 & 0.802 & 3.50 & \\
\hline C0421 & 86.3 & 167.9 & 0.786 & 3.33 \\
\hline C0430 & 94.7 & 202.9 & 0.726 & 3.37 & \\
\hline C1007 & 79.9 & 210.7 & 0.542 & 2.37 & \\
\hline C1014 & 69.5 & 183.0 & 0.382 & 1.84 & \\
\hline C1021 & 141.9 & 375.4 & 0.785 & 4.05 & \\
\hline C2001 & 108.1 & 271.2 & 0.802 & 3.75 & \\
\hline C2003 & 104.3 & 250.2 & 0.746 & 3.34 & \\
\hline C2005 & 65.8 & 173.1 & 0.463 & 2.08 \\
\hline N0000 & 159.7 & 353.2 & 0.877 & 4.59 & \\
\hline N0407 & 125.7 & 293.1 & 0.865 & 4.17 & \\
\hline N0414 & 121.7 & 296.1 & 0.840 & 4.08 & \\
\hline N0421 & 85.3 & 211.6 & 0.647 & 2.87 & \\
\hline N0430 & 114.3 & 224.1 & 0.815 & 3.77 & \\
\hline N1003 & 99.5 & 239.5 & 0.876 & 3.90 & \\
\hline N1007 & 79.5 & 183.5 & 0.620 & 2.65 & \\
\hline N1014 & 117.5 & 268.1 & 0.801 & 3.93 & \\
\hline N1021 & 108.2 & 248.7 & 0.821 & 3.81 & \\
\hline N2001 & 62.6 & 146.0 & 0.862 & 3.63 & \\
\hline N2003 & 109.4 & 265.1 & 0.799 & 3.63 & \\
\hline N2005 & 82.8 & 161.3 & 0.775 & 3.37 & \\
\hline N2007 & 69.2 & 156.9 & 0.614 & 2.53 & \\
\hline & & & & & \\
\hline
\end{tabular}

aSample, Coded samples: $C N N N N=$ nabak, NNNNN = dongchimi

${ }^{\mathrm{b}}$ Number of OTUs, based on 1000 random reads for each coded sample

${ }^{\circ}$ Diversity indices, as described in Materials and Methods 


\section{Figure Legends}

364 Figure 1: Physiochemical Data $\left(4^{\circ}, 10^{\circ}\right.$, and $\left.20^{\circ}\right)$. The $\mathrm{pH}(\mathrm{A})$ and titratable acidity (B) are

365 shown, with the data for $4^{\circ} \mathrm{C}$ (circles), $10^{\circ} \mathrm{C}$ (triangles), and $20^{\circ} \mathrm{C}$ (squares). Data for the

366 dongchimi (unsliced) samples are represented by the filled symbols, and the nabak (sliced)

367 samples are represented by the open symbols.

368 Figure 2: Lactic and Acetic Acid Data $\left(4^{\circ}, 10^{\circ}\right.$, and $\left.20^{\circ}\right)$. The lactic acid concentrations (A) and

369 acetic acid concentrations (B) are shown, with the data for $4^{\circ} \mathrm{C}$ (circles), $10^{\circ} \mathrm{C}$ (triangles), and

$37020^{\circ} \mathrm{C}$ (squares). Dongchimi (unsliced) samples are represented by the filled symbols, and the

371 nabak (sliced) samples are represented by the open symbols.

372 Figure 3: Sugar Concentrations $\left(4^{\circ}, 10^{\circ}\right.$, and $\left.20^{\circ}\right)$. The glucose (A) and fructose (B)

373 concentrations are shown, with the data for $4^{\circ} \mathrm{C}$ (circles), $10^{\circ} \mathrm{C}$ (triangles), and $20^{\circ} \mathrm{C}$ (squares).

374 Dongchimi (unsliced) samples are represented by the filled symbols, and the nabak (sliced)

375 samples are represented by the open symbols.

376 Figure 4: Microbial Cell Counts $\left(4^{\circ}, 10^{\circ}\right.$, and $\left.20^{\circ}\right)$. The PCA (A) and MRS (B) cell count data are

377 shown, with the data for $4^{\circ} \mathrm{C}$ (circles), $10^{\circ} \mathrm{C}$ (triangles), and $20^{\circ} \mathrm{C}$ (squares). Dongchimi (unsliced)

378 samples are represented by the filled symbols, and the nabak (sliced) samples are represented by

379 the open symbols.

380 Figure 5: Relative Abundance Data of microbiota for nabak (sliced) Kimchi. The relative

381 abundance for nabak fermentations at (A) $4^{\circ} \mathrm{C}$, (B) $10^{\circ} \mathrm{C}$, and (C) $20^{\circ} \mathrm{C}$ are shown. The color

382 codes for each population are as indicated in the legend. 
383 Figure 6: Relative Abundance Data for dongchimi (unsliced) Kimchi. The relative abundance 384 data for dongchimi fermentations at (A) $4^{\circ} \mathrm{C}$, (B) $10^{\circ} \mathrm{C}$, and (C) $20^{\circ} \mathrm{C}$ are shown. The color codes 385 for each population are as indicated in the legend.

386 Figure 7. Changes in phyla for watery kimchi samples. The Firmicutes (upward triangles) and 387 Proteobacteria (downward triangles) are shown for samples at $4^{\circ} \mathrm{C}(\mathrm{A}), 10^{\circ} \mathrm{C}(\mathrm{B})$, and $20^{\circ} \mathrm{C}(\mathrm{C})$ 388 fermentations for both nabak (open symbols) and dongchimi (filled symbols).

389 Figure 8: Clustering watery kimchi samples. The UPGMA tree (A) where color of nodes 390 indicates continuous confidence level of $100 \%$ orange to $30 \%$ blue, and the score plot of 391 principal component analysis (B) are shown. 0 d, green squares; $4^{\circ} \mathrm{C}$, red triangles; $10^{\circ} \mathrm{C}$, blue 392 triangles; $20^{\circ} \mathrm{C}$, orange triangles. 


\section{Figure $1, \mathrm{pH}$ Changes at $4^{\circ}, 10^{\circ}$, and $20^{\circ}$}

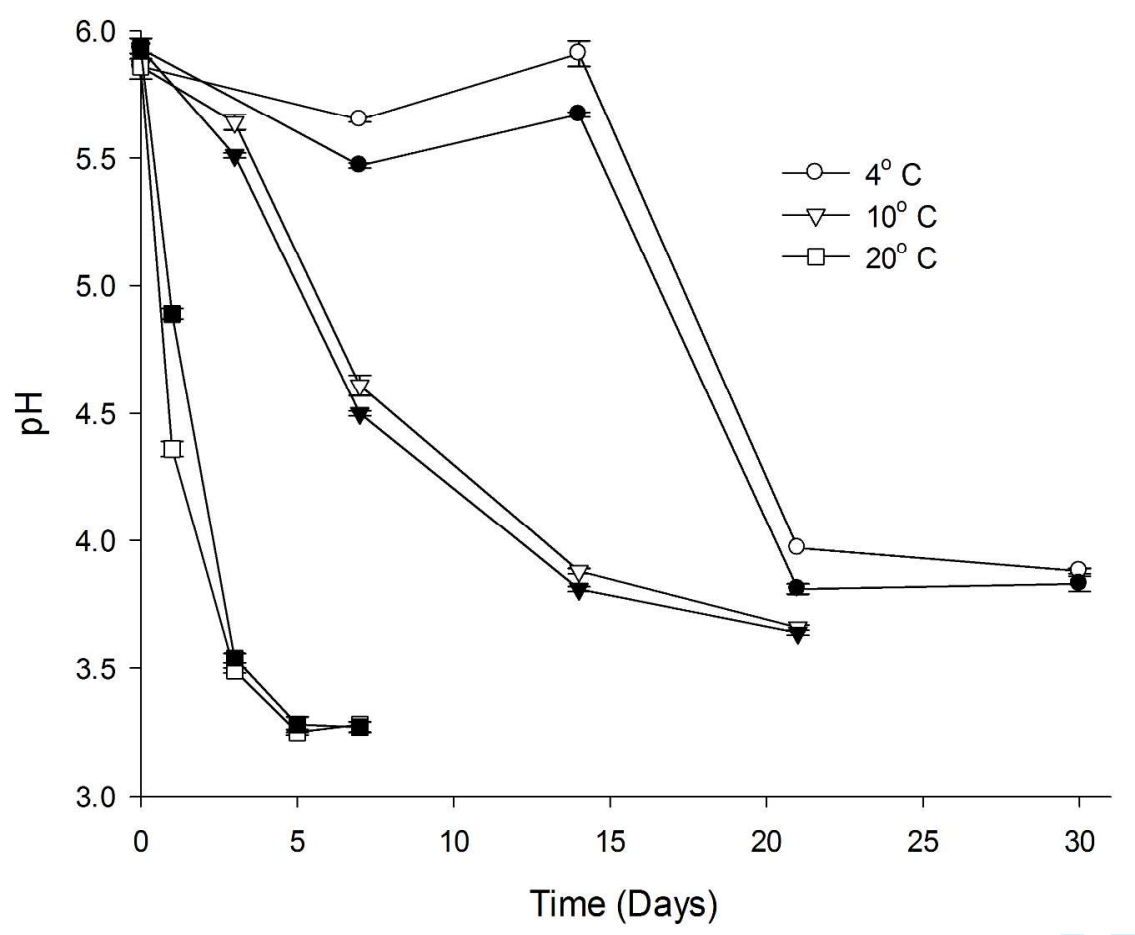

395 Physiochemical Data $\left(4^{\circ}, 10^{\circ}\right.$, and $\left.20^{\circ}\right)$. The $\mathrm{pH}(\mathrm{A})$ and titratable acidity $(\mathrm{B})$ are shown, with the

396 data for $4^{\circ} \mathrm{C}$ (circles), $10^{\circ} \mathrm{C}$ (triangles), and $20^{\circ} \mathrm{C}$ (squares). Data for the dongchimi (unsliced)

397 samples are represented by the filled symbols, and the nabak (sliced) samples are represented by 398 the open symbols. 


\section{Figure 2, Lactic and Acetic Acid Data}
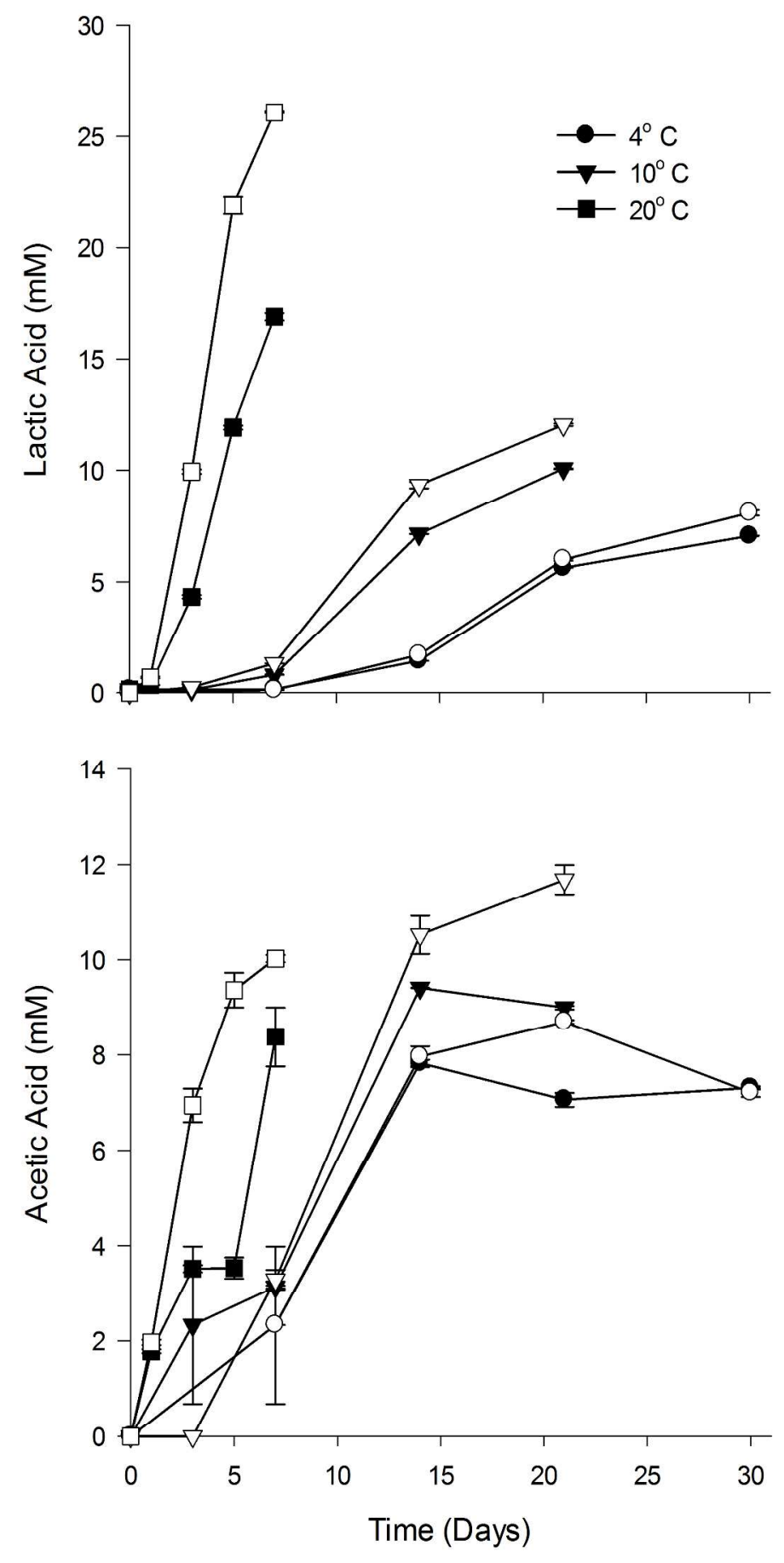

400 Lactic and Acetic Acid Data $\left(4^{\circ}, 10^{\circ}\right.$, and $\left.20^{\circ}\right)$. The lactic acid concentrations (A) and acetic acid

401 concentrations (B) are shown, with the data for $4^{\circ} \mathrm{C}$ (circles), $10^{\circ} \mathrm{C}$ (triangles), and $20^{\circ} \mathrm{C}$ 
402 (squares). Dongchimi (unsliced) samples are represented by the filled symbols, and the nabak 403 (sliced) samples are represented by the open symbols. 


\section{Figure 3 , Sugar concentrations}
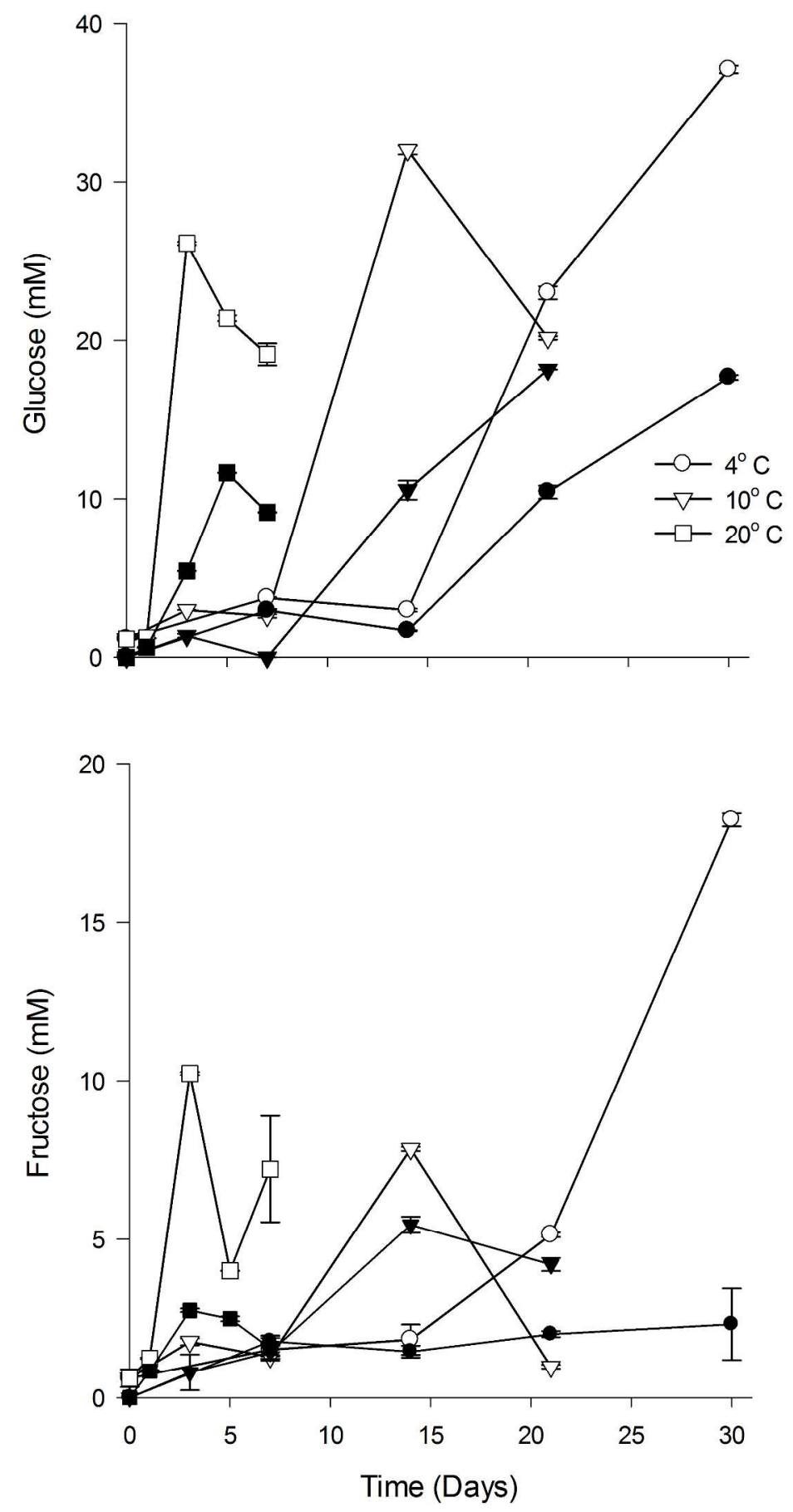

405 Sugar Concentrations $\left(4^{\circ}, 10^{\circ}\right.$, and $\left.20^{\circ}\right)$. The glucose $(\mathrm{A})$ and fructose $(\mathrm{B})$ concentrations are

406 shown, with the data for $4^{\circ} \mathrm{C}$ (circles), $10^{\circ} \mathrm{C}$ (triangles), and $20^{\circ} \mathrm{C}$ (squares). Dongchimi (unsliced) 
407 samples are represented by the filled symbols, and the nabak (sliced) samples are represented by 408 the open symbols. 


\section{Figure 4, Microbial Cell Counts}
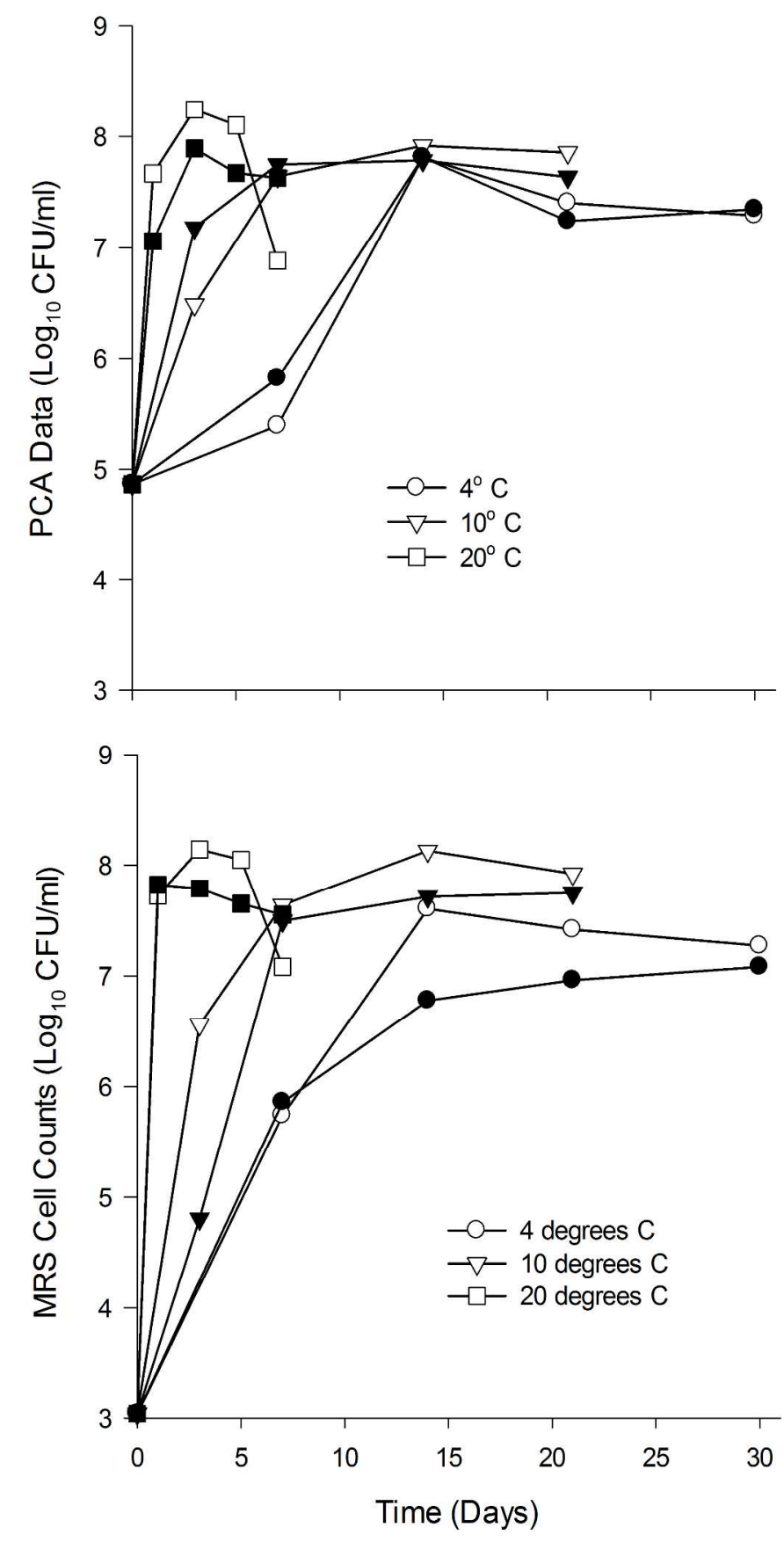

409

410 Microbial Cell Counts $\left(4^{\circ}, 10^{\circ}\right.$, and $\left.20^{\circ}\right)$. The PCA (A) and MRS (B) cell count data are shown,

411 with the data for $4^{\circ} \mathrm{C}$ (circles), $10^{\circ} \mathrm{C}$ (triangles), and $20^{\circ} \mathrm{C}$ (squares). Dongchimi (unsliced) 
412 samples are represented by the filled symbols, and the nabak (sliced) samples are represented by 413 the open symbols. 


\section{Figure 5 , Nabak (Sliced) Microbiota}

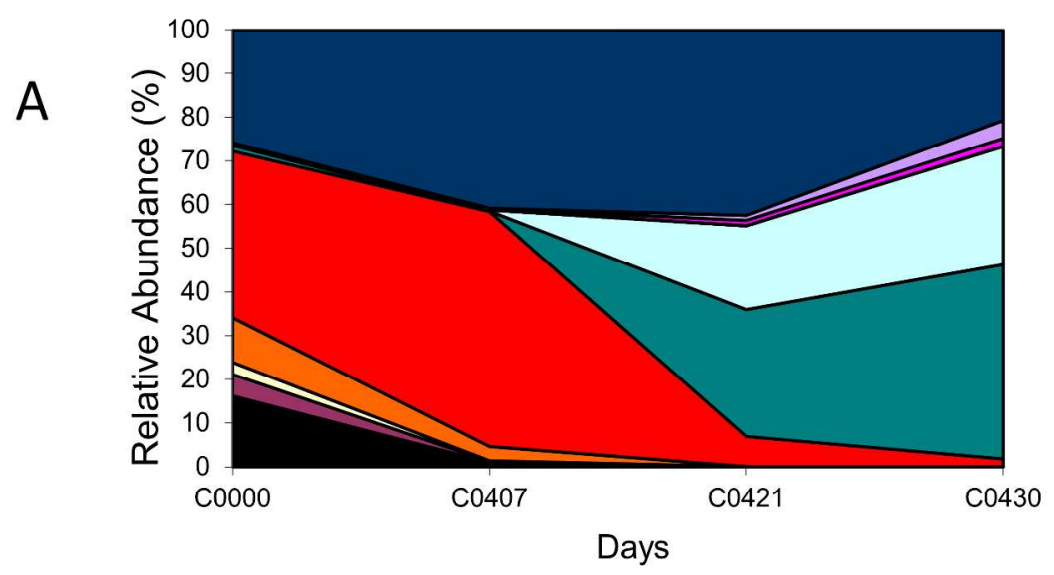

B
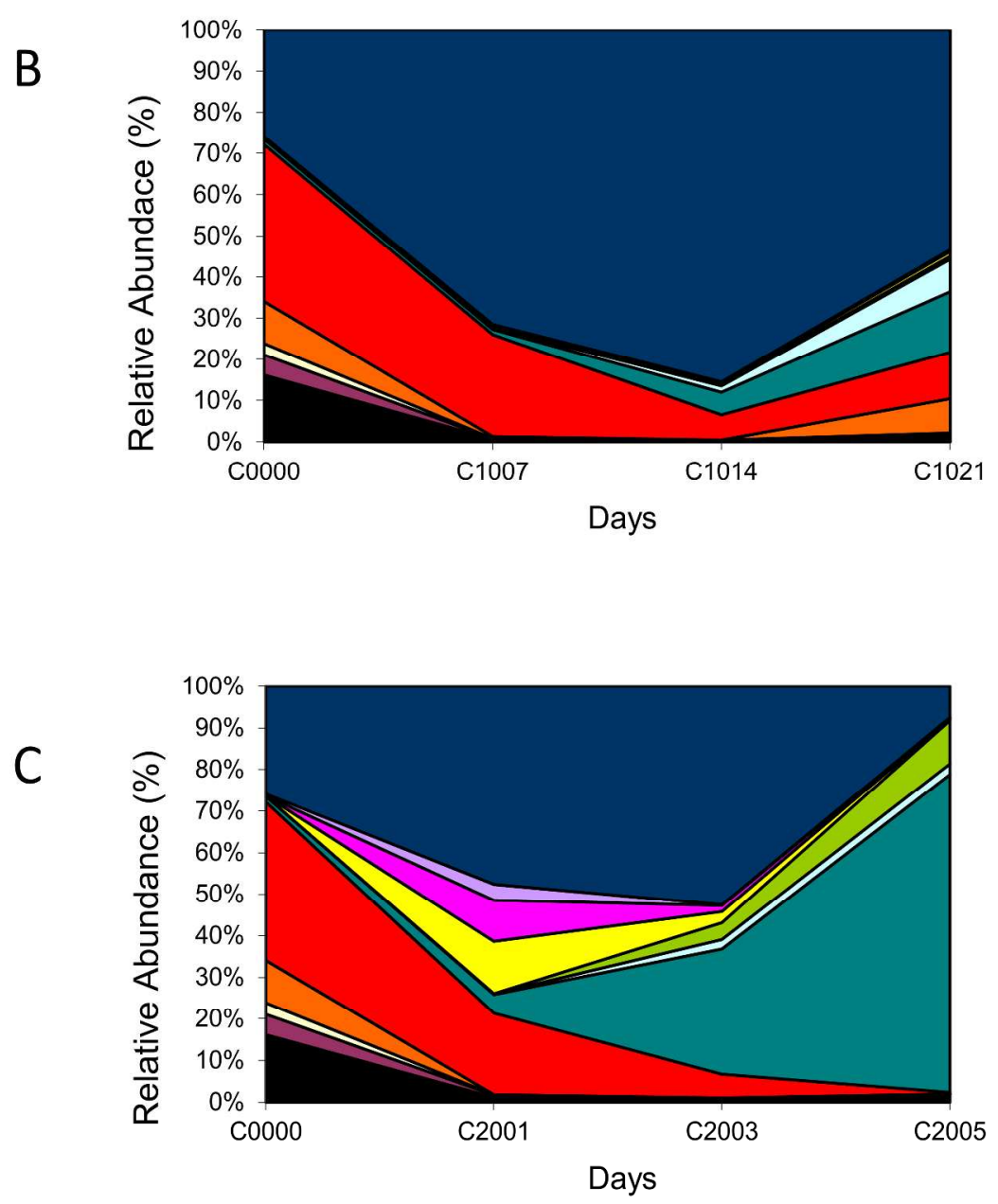

414 
415 Relative Abundance Data of microbiota for nabak (sliced) Kimchi. The relative abundance for 416 nabak fermentations at (A) $4^{\circ} \mathrm{C}$, (B) $10^{\circ} \mathrm{C}$, and (C) $20^{\circ} \mathrm{C}$ are shown. The color codes for each 417 population are as indicated in the legend. 


\section{Figure 6 , Dongchimi (Unscliced) Microbiota}
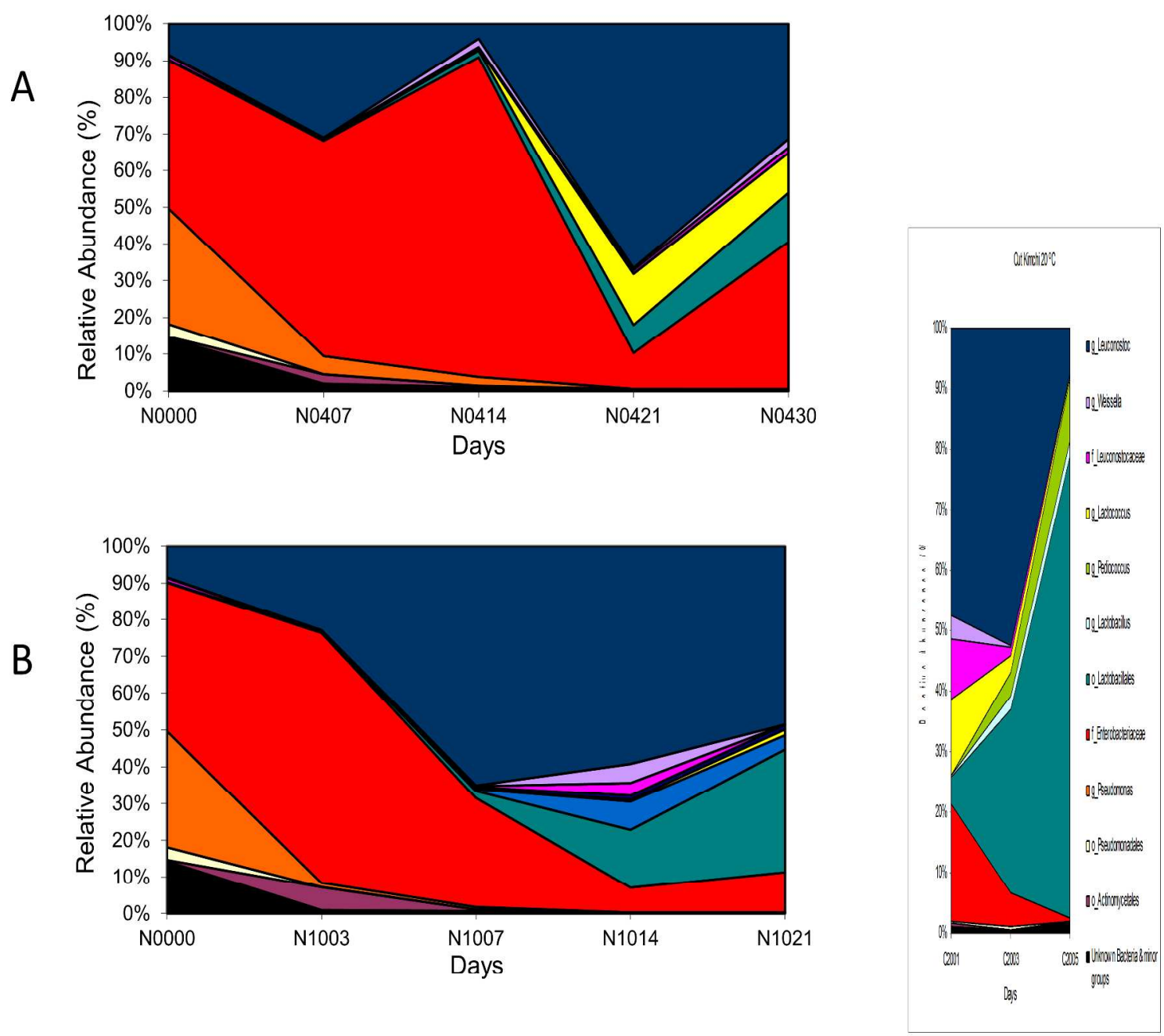

418

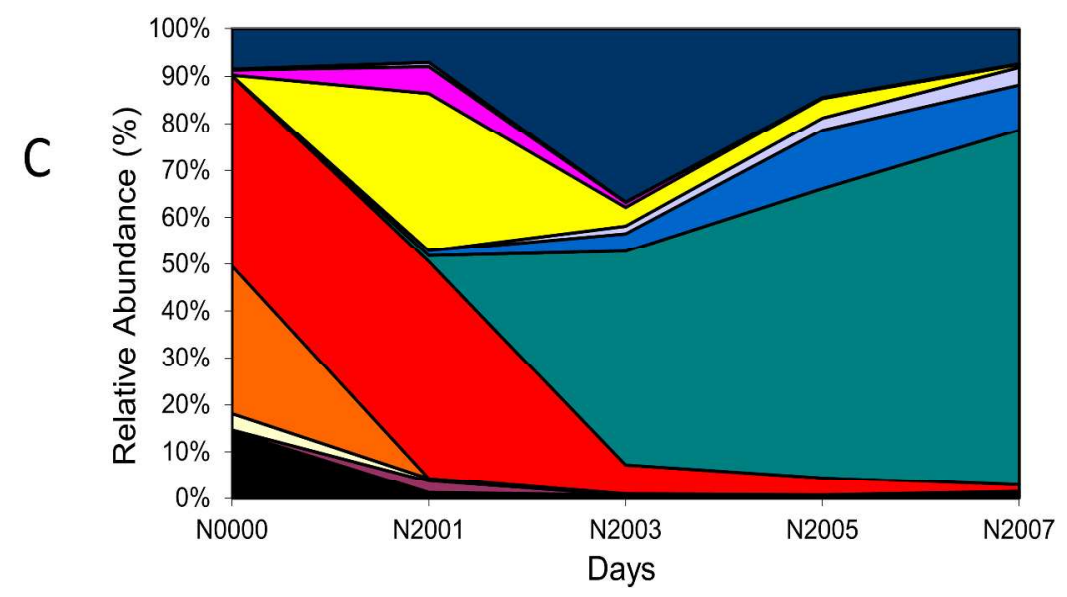


419 Relative Abundance Data for dongchimi (unsliced) Kimchi. The relative abundance data for

420 dongchimi fermentations at (A) $4^{\circ} \mathrm{C}$, (B) $10^{\circ} \mathrm{C}$, and (C) $20^{\circ} \mathrm{C}$ are shown. The color codes for each

421 population are as indicated in the legend. 
422 Figure 7. Changes in phyla for watery kimchi samples.

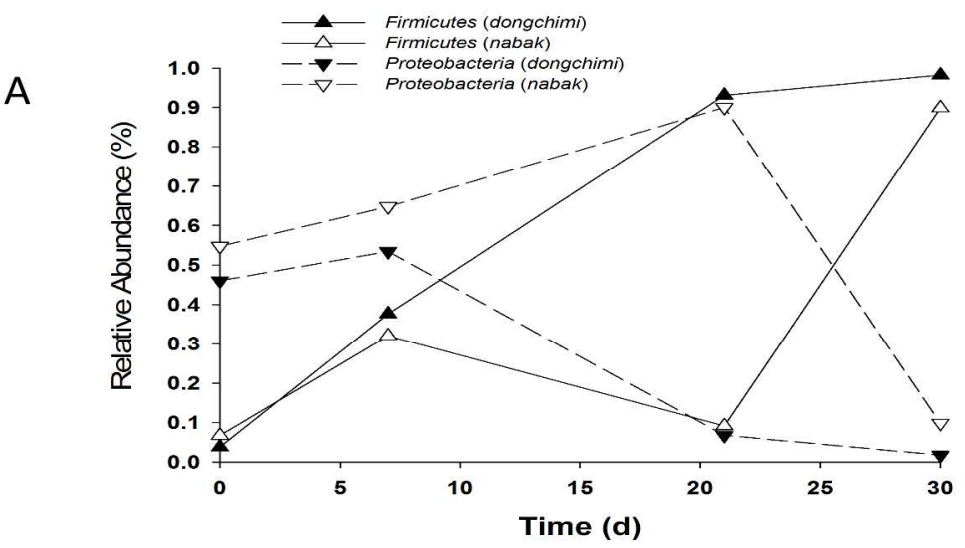

B

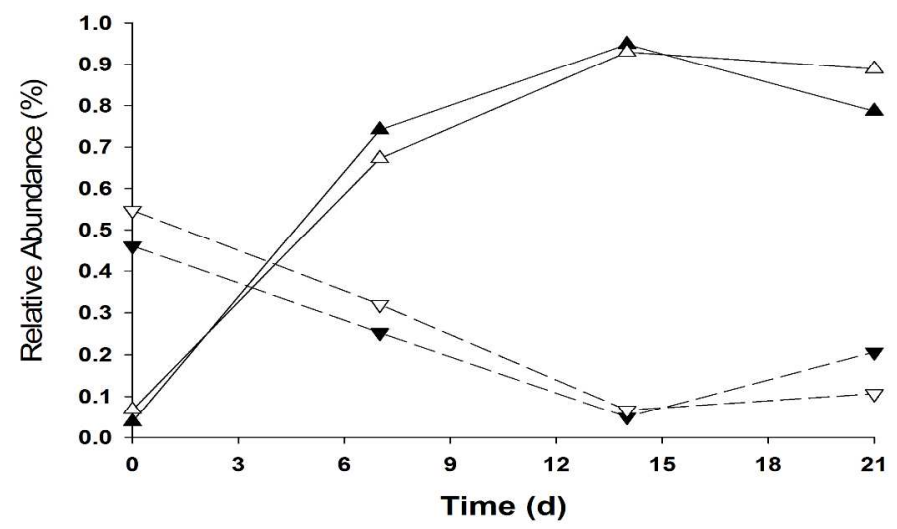

C

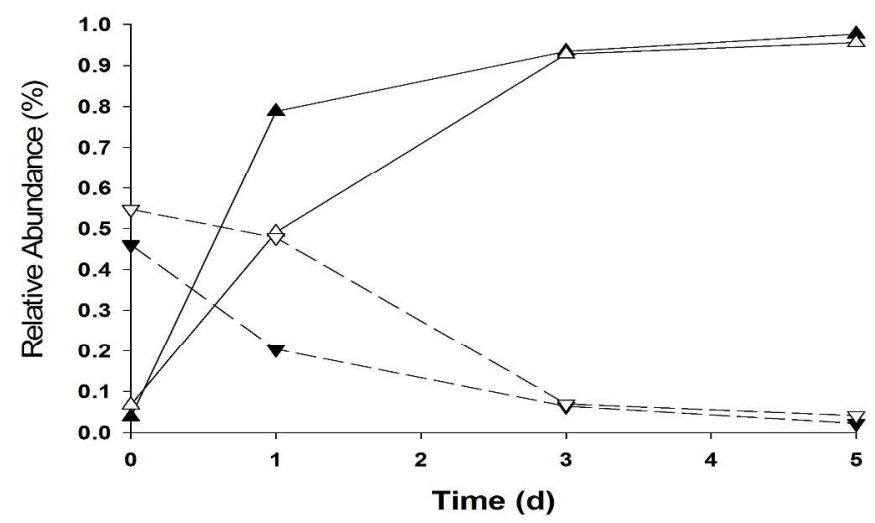

424 The Firmicutes (upward triangles) and Proteobacteria (downward triangles) are shown for

425 samples at $4^{\circ} \mathrm{C}(\mathrm{A}), 10^{\circ} \mathrm{C}(\mathrm{B})$, and $20^{\circ} \mathrm{C}(\mathrm{C})$ fermentations for both nabak (open symbols) and 426 dongchimi (filled symbols). 
427 Figure 8, Clustering of nabak and dongchimi samples.

428

429

430

(A)

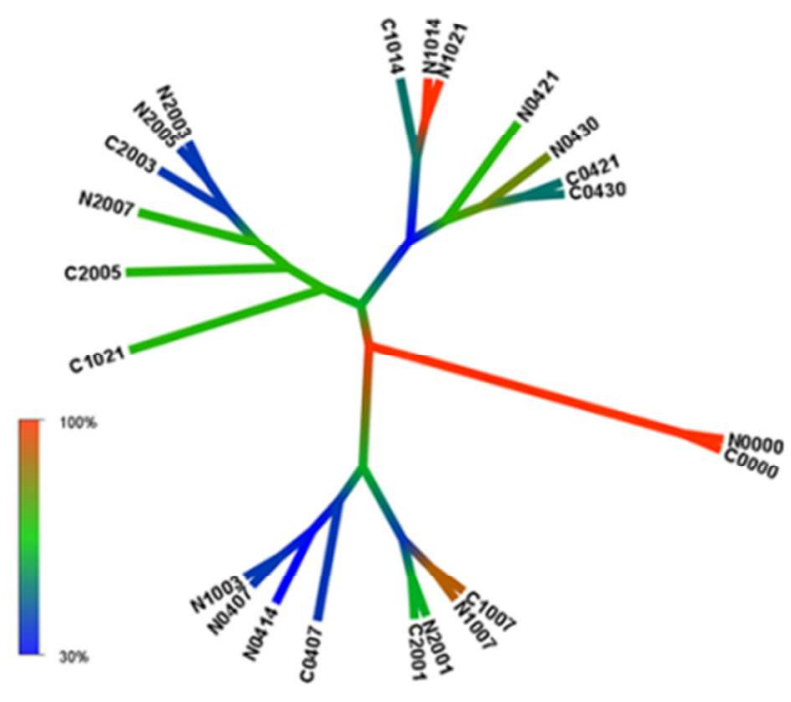

(B)

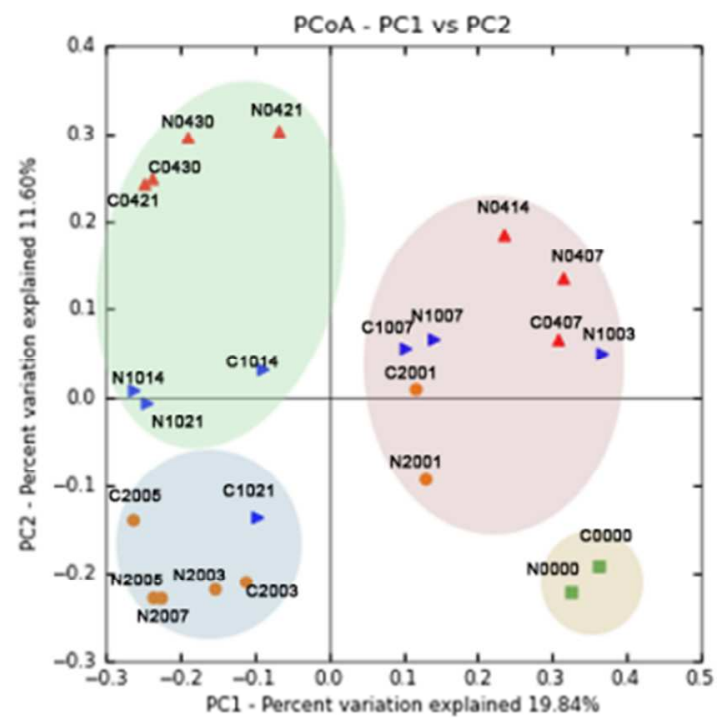

431

432

433 continuous confidence level of $100 \%$ orange to $30 \%$ blue, and the score plot of principal

434 component analysis (B) are shown. 0 day, green squares; $4^{\circ} \mathrm{C}$, red triangles; $10^{\circ} \mathrm{C}$, blue triangles;

$43520^{\circ} \mathrm{C}$, orange triangles. 